\title{
A Review of Factors Influencing Collaborative Relationships
}

\author{
María-José Verdecho, Juan-José Alfaro-Saiz, and Raúl Rodríguez-Rodríguez \\ Department of Business Organization, CIGIP, \\ (Research Centre on Production Management and Engineering), \\ Universitat Politècnica de València, Camino de Vera, s/n, 46022, Valencia, Spain \\ \{mverdecho, jalfaro, raurodro\} @cigip.upv.es
}

\begin{abstract}
Collaboration is a term commonly used to refer to a type of interorganizational relationship. However, in real business assessments, many collaborative relationships fail due to the lack of understanding of the factors influencing collaboration sustainability. For this reason, enterprises, prior to engage to a collaborative relationship, need to understand further which the main factors influencing collaboration relationships are, how they are structured and how they interact so that decision makers that desire to engage in a collaborative relationship/network focus not only on improving performance indicators but also on the factors that influence the results of those performance indicators. The purpose of this paper is to present a critical literature review of factors influencing collaborative relationships in order to perform a comparative study of the works for identifying main strengths and gaps for future research.
\end{abstract}

Keywords: Collaboration, collaborative networks, conceptual issues.

\section{Introduction}

In the current complex business environment, enterprises adopt different strategies and business models to remain competitive in the marketplace. In order to be efficient, enterprises focus on their own core competencies and rely on other enterprises for developing activities that are related to non-core competences. In fact, enterprises engage in diverse types of relationships that differ in their scope and broadness ranging from transactional type (punctual relationship) to collaborative relationship (long-term relationship). Enterprises must know which type of relationship they need to engage as not all types of relationships are suitable for all the business purposes. For example, in [1], it is presented a classification of four types of relationships among organizations depending on the degree of interaction: networking, coordinated networking, cooperation and collaboration. From a global perspective, collaboration relationships are the ones that involve the greatest degree of interaction and, for that reason, are the most complex. Collaboration involves two or more independent enterprises working together to align their processes with the goal of creating value to end customers and stakeholders with greater success than acting alone [2]. However, collaborative relationships may fail if they are not properly 
managed [3-4]. The Supply Chain Management Review and Computer Science Corporation [5] performed a survey and observes that collaboration is cited as the single most important topic; but how to achieve it is not well understood. The survey showed that 44 percent of the organizations in the sample have functions specifically for supplier and customer collaboration. However, only about 35 percent of the collaboration initiatives turned out to be even moderately successful. As [4] suggest, perhaps, it is because not all participants in every supply chain have embedded collaborative values. In [6], it is indicated that the lack of understanding of collaboration structure and dynamics is considered the main cause of failure of collaborative initiatives. Then, it seems important that enterprises that desire to engage into a collaborative relationship understand the complexity of collaboration, which are the main factors influencing collaboration, how they are structured and how they interact so that so that decision makers that desire to engage in a collaborative relationship/network focus not only on improving performance indicators but also on the factors that influence the results of those performance indicators.

The aim of this paper is twofold. The first purpose is to provide a literature review of works that analyze factors influencing collaborative relationships (section 2). The second purpose is to perform a comparative study of the works reviewed for identifying main strengths and gaps for future research (section 3 and 4).

\section{Literature Review}

In this section, it is presented a review of works that deal with inter-organizational and collaborative relationships in order to analyze the factors that influence interorganizational relationships (in general) and collaborative relationships (in particular). It has to be noted that inter-organizational relationships embed all types of relationships, as collaborative relationships are the most complex type involving the greatest degree of interaction. From the literature review, a typology composed of three groups has been defined (see Fig. 1).

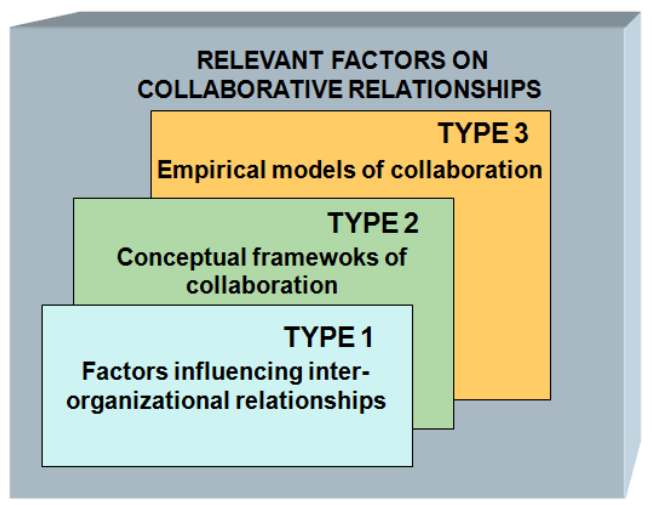

Fig. 1. Relevant factors influencing collaborative relationships: a typology 
The first group consists of works that identify factors influencing interorganizational relationships (type 1). The second group present works that propose conceptual frameworks of collaboration (type 2), and finally, the third group is composed by works that present empirical models of collaboration (type 3 ). The typology is then structured from a lower to a higher degree of interaction among factors (type 1 only describe some conceptual interaction among factors, type 2 structures the interaction among factors under a conceptual framework and type 3 structures the interaction among factors under a framework and quantifies their relationships empirically).

\subsection{Works That Identify Factors Influencing Inter-organizational Relationships}

There are numerous works in literature that deal with inter-organizational relationships. It is out of the scope of this paper to review all these works, but a selection has been performed with the aim of identifying the main factors influencing inter-organizational relationships. Within this group of the typology, we have considered two main subgroups of works. One subgroup consists of works that present classifications of inter-organizational environments according to the level of maturity reached in different aspects of their relationships, i.e. they present supply chain evolutionary models (from lower to higher level of collaboration). Within this subgroup, in [3], it is presented a supply chain classification depending on two main aspects: strategic value of the relationship and technology used to support it. From a process perspective, in [7], it is developed a model to classify supply chains based on the maturity of their processes. Each level is characterized according to different factors such as alignment of processes, organizational structure, cooperation, process performance and trust. In [8], a typology for supply chain characterization related to Fiske [9] social relationships theory and the interdependence concept is exposed. In [10], it is presented a classification of supply chains according to the presence of three factors in the CPFR (Collaborative Planning, Forecasting and Replenishment) process: collaboration form, ICT and coordination mechanisms. In [1], organization relationships are classified into four groups depending on four types of factors: communication and information shared; complementary, compatible and/or joint objectives; activity alignment and joint responsibility. In addition, the authors highlight the need of measuring collaborative performance and importance of relationships attributes such as trust.

The second subgroup comprises works that identify the main factors influencing partnerships. In [11] it is considered five factors of inter-organizational relationships: degree of absolute and relative commitment, symmetry of rewards, extent of uncertainty, degree of mutual trust, and length of the relationship. [12] identifies seven factors for partnering contexts: business processes, people, trust, technology, structure, financial resources and culture. [13] analyzes eight factors from different disciplines of theory (marketing, economy, strategy and management) that may influence the evolution on supply chain management. The eight factors are: trust, power, dependency, economy, collaboration, assets, risk and communication.

From the review, we can group the key factors influencing inter-organizational relationships into: strategic value of the relationship and goal congruence; information shared; ICT and Information Systems (IS) role; joint decision-making, activities and 
problem solving; process approach and management levels; relationship attributes such as trust, commitment, interdependence and coordination; equity or symmetry of investments, risks and rewards; and performance measurement.

\subsection{Conceptual Frameworks of Collaboration}

In this work, a conceptual framework that characterizes collaboration is defined as 'the set of elements that organized and interrelated allow the representation of the collaboration relationships within inter-organizational environments in a generic manner'. [14] proposes a conceptual framework that associates variables of relationships (commitment, cooperation, interdependence/power, technology, trust, mutual goals, etc.) to different stages in relationship process (partner selection, defining purpose, setting relationship boundaries, creating relationship value and relationship maintenance). It exposes the interaction among some of the variables describing how they may evolve when an event happens during the different stages. Nevertheless, the work could be further extended by including collaborative processes and performance measurement.

In [15], it is developed a conceptual framework for cross-enterprise collaboration that identifies processes, competencies and capabilities. Key process performance objectives for each process are established. In this sense, the inclusion of performance objectives for the leadership process sustained by the 'relationships' competence is noticeable. However, the relationships competence does not consider important relational attributes e.g. trust.

[16] presents a conceptual framework structured in three levels: strategic, collaborative and cultural elements. The framework considers inter-organizational process alignment through the organizations, performance indicators for the whole $\mathrm{SC}$, the connection between SC performance indicators and the cultural elements, and identifies technology as strategic factor. However, the connection among some of the elements is not explicit. For instance, there is no direct connection between performance indicators and joint decision-making.

Other works reviewed are [17], [18], [19], [20] and [21]. From the review, we can conclude that although the reviewed conceptual frameworks present some aspects that can be extended, they are a foundation for understanding which are the main factors and interrelations influencing collaborative relationships. Therefore, these works facilitate to analyse further the connection of these collaborative factors although they do not use quantitative techniques that allow measuring the degree of influence among the different factors what is reviewed on the next type of works.

\subsection{Empirical Models of Collaboration}

The works presenting empirical models have gained attention in the literature in the last years as they test relationships among variables (factors) based on real data. [22] develop a model of commitment-trust theory suggesting that trust and commitment are mediating variables between other factors such as cooperation, conflicts, communication, opportunism and benefits.

[23] identify from an empirical study the characteristics that contribute to successful partnerships: relationship attributes (coordination, commitment, and trust), 
communication behaviour (participation, and communication quality) and joint problem solving techniques.

The works [24], [25], [26] and [27] expose models with trust as a key factor to increase commitment in relationships as well as a mediator between commitment and the other collaboration factors. The authors suggest that commitment improves with a higher degree of adaptation, shared values, communication, satisfaction and cooperation. [28] presents a model with interdependence, commitment and trust factors. This work details that there is two types of commitment, calculated and affective, and analyze to what extent they are influenced by interdependence and trust in the supply chain. [26] also distinguish types of commitment: affective, continuity and normative. The work aims to study the impact of affective and continuity commitment in supply chain integration and increases coordination among partners. On the other side, normative commitment allows establishing objectives and shared values. Other works, [29] and [30] do not include in their works the commitment factor but they consider trust an essential factor of collaboration. [29] analyze the impact of three factors: trust, ICT, and information network on the joint efforts (planning and conflict resolution). In [30] trust is a mediator factor between other factors such as participation, communication, learning capability, and ability to share knowledge to finally obtain inter-organizational knowledge share. Other works reviewed include [31] and [32].

After analyzing the works it is observed that there is not a consensus reached among the authors regarding what are the main factors of collaborative relationships and which are the influences among them. In fact, there are some factors, e.g. trust that is modeled in two different manners (mediator variable and dependent variable). It has to be noted that the most modeled factors are trust, commitment and communication. Each work establishes different objectives for their models but the most commonly used dependent variable are joint action, trust and commitment. This means that this type of models mostly try to analyze the effects of the other collaborative factors on these three factors in order to achieve sustainable relationships.

\section{Comparative Study}

Table 1 presents a comparative study of the works reviewed. For that purpose, eight most commonly cited factors have been considered so that different perspectives of enterprises are covered: strategic, process, culture, communication infrastructure and performance measurement (management). This is because the works that integrate different enterprise perspectives constitute a sound basis for understanding collaboration relationship dynamics. The reviewed factors are: common strategy $(\mathrm{S})$, collaborative processes (P), collaborative culture (in general) (CC), trust (T), commitment (C), information shared (IS), ICT and performance measurement (PM). The criteria established to compare the works ranges from absence of the factor (blank) to high degree of consideration (++). 
Table 1. Comparative study of the works reviewed

\begin{tabular}{|c|c|c|c|c|c|c|c|c|c|}
\hline Tip. & References & S & $\mathrm{P}$ & $\mathrm{CC}$ & $\mathrm{T}$ & $\mathrm{C}$ & IS & ICT & $\mathrm{PM}$ \\
\hline \multirow{8}{*}{1} & Birnbirg (1998) & & & + & ++ & ++ & & + & + \\
\hline & Boddy et al. (2000) & + & + & + & & & & + & + \\
\hline & Sabath and Fontanella (2002) & ++ & + & + & & & + & ++ & \\
\hline & Handfield and Bechtel (2004) & + & & + & ++ & & ++ & & + \\
\hline & $\begin{array}{l}\text { Lockamy and McCormack } \\
\text { (2004) }\end{array}$ & + & ++ & + & + & & + & & + \\
\hline & Lejeune and Yakova (2005) & + & & + & ++ & & ++ & & \\
\hline & Danese (2006) & + & & + & & & + & ++ & \\
\hline & Camarinha-Matos et al. (2009) & ++ & + & + & + & + & + & + & + \\
\hline \multirow{8}{*}{2} & Wilson (1995) & + & & + & + & + & + & + & + \\
\hline & Bowersox et al. (2003) & ++ & ++ & + & & + & ++ & ++ & + \\
\hline & Barratt (2004) & + & ++ & + & + & + & + & + & + \\
\hline & Min et al. (2005) & ++ & ++ & + & & & ++ & + & + \\
\hline & $\begin{array}{l}\text { Simatupang and Sridharan } \\
\text { (2005) }\end{array}$ & ++ & ++ & + & + & + & ++ & ++ & + \\
\hline & Burgess and Singh (2006) & ++ & ++ & + & + & & ++ & ++ & + \\
\hline & Giannakis (2007) & ++ & ++ & + & ++ & ++ & + & + & \\
\hline & Gruat La Forme et al. (2007) & + & ++ & + & & & ++ & & + \\
\hline \multirow{11}{*}{3} & Morgan and Hunt (1994) & + & & ++ & ++ & ++ & ++ & & + \\
\hline & Mohr and Spekman (1994) & & & ++ & ++ & ++ & ++ & & + \\
\hline & Geyskens et al. (1996) & & & + & ++ & ++ & & & \\
\hline & Zineldin and Jonsson (2000) & + & & ++ & ++ & ++ & ++ & & + \\
\hline & Coote et al. (2003), & & & ++ & ++ & ++ & ++ & & \\
\hline & Wu et al. (2004) & + & ++ & ++ & ++ & ++ & ++ & & \\
\hline & Handfield and Bechtel (2002) & + & & + & ++ & & ++ & & + \\
\hline & Kwon and Suh (2005) & & & + & ++ & ++ & & ++ & \\
\hline & Pimentel et al. (2006) & & & + & ++ & & ++ & & \\
\hline & Matopoulos et al. (2007) & + & ++ & + & + & & ++ & ++ & \\
\hline & Cheng et al. (2008) & + & & + & ++ & & ++ & + & \\
\hline
\end{tabular}

\section{Conclusions and Research Implications}

From the table, the main conclusion obtained is that there is not a consensus regarding what are the main factors of collaborative relationships and which are the influences among them. First, the different groups present different insight into the factors. For example, type 2 and 3 provide more insight than type 1 . However, type 2 and 3 differ on the factors treated. Type 2 deepens more on strategy, processes, information shared and ICT while type 3 deepens more on collaborative culture, trust, commitment and information shared. It has to be noted that other factors such as performance measurement are only treated in low detail in these works. Thus, one future research line is to analyse how performance measurement frameworks developed for collaborative enterprises can be connected to the conceptual frameworks and empirical models reviewed in this work to conceptualize further and measure factors influencing collaborative relationships. 
Second, the interrelations among collaborative elements identified by the different works of type 2 and 3 of the typology differ and only cover some of the factors. Even in the type 3, there are some factors, e.g. trust that is modeled in two different manners (mediator variable and dependent variable). Further research is needed to model all the factors influencing collaborative relationships, establishing the interactions among them and quantifying under the same model all the existing influences. It may seem that complex models do not capture the essence of what is analysed. However, simple models do not capture the dynamics of complex phenomena. Further research should encounter a balance of both aspects for the different situations.

Third, some interactions among factors have been analysed in more detail e.g. trust and commitment, while other interesting interactions have been less treated e.g. strategy and trust or strategy and performance measurement. Further research should consider these issues into their scope. Finally, it is important to note that it will be interesting to analyse combinations of all types of factors as all of them influence each other in a collaborative relationship.

\section{References}

1. Camarinha-Matos, L.M., Afsarmanesh, H., Galeano, N., Molina, A.: Collaborative networked organizations - Concepts and practice in manufacturing enterprises. Computers \& Industrial Engineering 57, 46-60 (2009)

2. Simatupang, T.M., Wright, A.C., Sridharan, R.: Applying the theory of constraints to supply chain collaboration. Supply Chain Management: An International Journal 9(1), 5770 (2004)

3. Sabath, R.E., Fontanella, J.: The Unfulfilled Promise of Supply Chain Collaboration. Supply Chain Management Review (July/August 2002)

4. Kampstra, R.P., Ashayeri, J., Gattorna, J.L.: Realities of supply chain collaboration. The International Journal of Logistics Management 17(3), 312-330 (2006)

5. Supply Chain Management Review (SCMR) and Computer Sciences Corporation, CSC (2004); The second annual global survey of supply chain progress, http: / / www. csc.com/

6. Busi, M., Bititci, U.S.: Collaborative performance management: present gaps and future research. International Journal of Productivity and Performance Management 55(1), 7-25 (2006)

7. Lockamy, A., McCormack, K.: The development of a supply chain management process maturity model using the concepts of business process orientation. Supply Chain Management: An International Journal 9(4), 272-278 (2004)

8. Lejeune, M.A., Yakova, N.: On characterizing the $4 \mathrm{C}$ 's in supply chain management. Journal of Operations Management 23(1), 81-100 (2005)

9. Fiske, A.P.: Relativity within Moose ("Mossi") culture: four incommensurable models for social relationships. Ethos 18, 180-204 (1990)

10. Danese, P.: Collaboration forms, information and communication technologies, and coordination mechanisms in CPFR. International Journal of Production Research 44, 3207-3226 (2006)

11. Birnbirg, J.C.: Control in interfirm co-operative relationships. Journal of Management Studies 25(4), 421-428 (1998)

12. Boddy, D., Macbeth, D., Wagner, B.: Implementing collaboration between organizations: an empirical study of supply chain partnering. Journal of Management Studies 37(7), 1003-1018 (2000) 
13. Handfield, R.B., Bechtel, C.: Trust, power, dependence, and economics: can SCM research borrow paradigms? International Journal of Integrated Supply Chain Management 1(1), 3-32 (2004)

14. Wilson, D.T.: An integrated model of buyer-seller relationships. In: Working Paper, Institute for the Study of Business Markets. The Pennsylvania State University, State College (1995)

15. Bowersox, D.J., Closs, D.J., Stank, T.P.: How to Master cross-enterprise Collaboration. Supply Chain Management Review (July/August 2003)

16. Barratt, M.: Understanding the meaning of collaboration in the supply chain. Supply Chain Management: An International Journal 9(1), 30-42 (2004)

17. Min, S., Roath, A.S., Daugherty, P.J., Genchev, S.E., Chen, H., Arndt, A.D.: Supply chain collaboration: what's happening? The International Journal of Logistics Management 16(2), 237-256 (2005)

18. Simatupang, T.M., Sridharan, R.: An integrative framework for supply chain collaboration. The International Journal of Logistics Management 16(2), 257-274 (2005)

19. Burgess, K., Singh, P.: A proposed integrated framework for analysing supply chains. Supply Chain Management: An International Journal 11(4), 337-344 (2006)

20. Gruat La Forme, F., Botta Genoulaz, V., Campagne, J.: A Framework to analyse Collaborative Performance. Computers in Industry 58, 687-697 (2005)

21. Giannakis, M.: Performance Measurement of Supplier Relationships. Supply Chain Management; An International Journal 12(6), 400-411 (2007)

22. Morgan, R.M., Hunt, S.D.: The Commitment-Trust Theory of Relationship Marketing. Journal of Marketing 58, 20-38 (1994)

23. Mohr, J., Spekman, R.: Characteristics of partnership success: Partnership attributes, communication behavior, and conflict resolution techniques. Strategic Management Journal 15(2), 135-152 (1994)

24. Zineldin, M., Jonsson, P.: An examination of the main factors affecting trust/commitment in supplier-dealer relationships: an empirical study of the Swedish wood industry. The TQM Magazine 12(4), 245-256 (2000)

25. Coote, L.V., Forrest, E.J., Tam, T.W.: An investigation into commitment in non-Western industrial marketing relationship. Industrial Marketing Management 32, 595-604 (2003)

26. Wu, W.T., Chiag, C.Y., Wu, Y.J., Tu, H.J.: The influencing factors of commitment and business integration on supply chain management. Industrial Management \& Data Systems 104(4), 322-333 (2004)

27. Kwon, I.K., Suh, T.: Trust, commitment and relationships in supply chain management: path analysis. Supply Chain Management: An International Journal 10(1), 26-33 (2005)

28. Geyskens, I., Steemkamp, J.B., Scheer, L.K., Kumar, N.: The effects of trust and interdependence on relationship commitment: A trans-Atlantic study. International Journal of Research in Marketing 13, 303-317 (1996)

29. Pimentel Claro, D., Borin de Oliviera Claro, P., Hagelaar, G.: Coordinating collaborative joint efforts with suppliers: the effects of trust, transaction specific investment and information network in the Dutch flower industry. Supply Chain Management: An International Journal 11(3), 216-224 (2006)

30. Cheng, J.H., Yeh, C.H., Tu, C.W.: Trust and knowledge sharing in green supply chains. Supply Chain Management: An International Journal 13(4), 283-295 (2008)

31. Matopoulos, A., Vlachopoulou, M., Manthou, V., Manos, B.: A conceptual framework for supply chain collaboration: empirical evidence from the agri-food industry. Supply Chain Management: An International Journal 12(3), 177-186 (2007)

32. Handfield, R.B., Bechtel, C.: The role of trust and relationship structure in improving supply chain responsiveness. Industrial Marketing Management 31, 367-382 (2002) 